Canadian

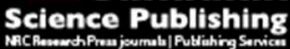

Canadian Geotechnical Journal

Revue canadienne de géotechnique

\title{
OPTIMUM LOCATION OF THE GEOGRID REINFORCEMENT IN UNPAVED ROAD
}

\begin{tabular}{|r|l|}
\hline Journal: & Canadian Geotechnical Journal \\
\hline Manuscript ID & cgj-2016-0562.R1 \\
\hline Danuscript Type: & Note \\
\hline Complete List of Authors: & $\begin{array}{l}\text { Mousavi, S. Hamed; North Carolina State University, Civil, Construction, } \\
\text { and Environmental Engineering } \\
\text { Gabr, Mo; North Carolina State University } \\
\text { Borden, Roy; North Carolina State University }\end{array}$ \\
\hline Keyword: & Reinforcement, geosynthetics, unpaved, location, finite element \\
\hline \multicolumn{2}{|c}{} \\
\hline
\end{tabular}


Mousavi, Gabr, Borden

\section{OPTIMUM LOCATION OF THE GEOGRID REINFORCEMENT IN UNPAVED ROAD}

\section{S. Hamed Mousavi, Corresponding Author}

North Carolina State University

Graduate Research Assistant, Department of Civil, Construction, and Environmental Engineering, North Carolina State University, Raleigh, NC 27695-7908;

Tel: 919-995-8792; Email: smousav3@,ncsu.edu

\section{Mohammed A. Gabr}

North Carolina State University

Professor, Department of Civil, Construction, and Environmental Engineering, North Carolina State University, Raleigh, NC 27695-7908;

Tel: 919-515-7904 FAX: 919-515-7908; Email: gabr@,eos.ncsu.edu

\section{Roy H. Borden}

North Carolina State University

Professor, Department of Civil, Construction, and Environmental Engineering, North Carolina State University, Raleigh, NC 27695-7908;

Tel: 919-515-7630 FAX: 919-515-7908; Email: borden@ncsu.edu 
Mousavi, Gabr, Borden

\section{ABSTRACT}

This study evaluated the optimum location of a reinforcement layer to maximize the efficiency of the reinforcement inclusion in an unpaved road section. The analyses are used to investigate the optimum location of the reinforcement layer within the aggregate base course, (ABC) layer, and explain possible reason for the improvement in performance. A series of 3D FEM analyses were performed, and the strain and stress response of a reinforced unpaved road section with two different $\mathrm{ABC}$ thicknesses was evaluated. The analyses were conducted under cyclic loading with three different radii of the circular loaded area. The embedded depth of reinforcement was varied within the $\mathrm{ABC}$ layer. Results indicated that regardless of $\mathrm{ABC}$ layer thickness, the surface deformation is minimized when the reinforcement is embedded at a depth equal to half of the radius of the loaded area, $(D=0.5 \mathrm{r})$. A higher tension force is mobilized in the reinforcement element when it is placed at $\mathrm{D}=0.5 \mathrm{r}$. It is also shown that the required thickness of $\mathrm{ABC}$ is reduced when the reinforcement layer is implemented at the depth at which the maximum vertical strain occurs. Depending on the thickness of the ABC layer, the FEA results indicated that reinforcement layer could be ineffectual if it is placed at the interface between the $\mathrm{ABC}$ and the subgrade layer as is traditionally the case.

Keywords: Reinforcement, geosynthetics, unpaved, location, finite element. 
Mousavi, Gabr, Borden

\section{INTRODUCTION}

Over the years, many studies have been performed to investigate the deformation behavior of the reinforced unpaved road. These included small-scale and large-scale laboratory testing and fullscale field tests as well as numerical and analytical analyses, (e.g. Fannin and Sigurdsson 1996; Hufenus et al. 2005; Leng and Gabr 2006; Tingle and Jersy 2009; Chen et al. 2009; Cote et al. 2010; White et al. 2011; Abu-Farsakh et al. 2011; Cowell et al. 2012; Thakur et al. 2012; Qian et al 2012; Saghebfar 2014; Tang et al. 2015; Sun et al. 2015; Palmeira and Gongora 2015). Several of these studies have been performed to evaluate the influence of factors such as the thickness of the aggregate base course $(\mathrm{ABC})$, shear strength and stiffness properties of subgrade, location of the reinforcement layer within the $\mathrm{ABC}$ layer, and mechanical and geometric properties of geogrid, on deformation response of a reinforced unpaved road. Geosynthetic inclusions have been shown to be more beneficial when the $\mathrm{ABC}$ layers are relatively thin; moreover, with an increase in the thickness of the $\mathrm{ABC}$, the contribution of the geosynthetic inclusion to the reduction of rut depth development decreases (Fannin and Sigurdsson 1996; Hufenus et al. 2006; Cote et al. 2010; Al-Qadi 2012). The results presented by Cancelli and Montanelli (1999), and Perkins (1999) indicated that the efficiency of geosynthetics reinforcement inclusion is more pronounced with soft subgrade soil. The optimum location of reinforcement layer has also been investigated (e.g. Perkins et al. 1999). Al-Qadi et al. (2012) recommended placing the reinforcement layer at the upper one-third of the $\mathrm{ABC}$ layer; however for the thinner $\mathrm{ABC}$ layer, the reinforcement should be located at the interface of the ABC and subgrade layer. Abu-Farsakh et al. (2011) reported similar results regarding the optimum location of a single layer of reinforcement; however, it was determined that double reinforcement layers inclusion (i.e., at the upper and lower third of the sample height) led to the largest improvement regardless of the geogrid type. Numerical study by Saad et al. (2006) indicated that the location which provides the highest 
Mousavi, Gabr, Borden

efficiency of reinforcement inclusion, regardless of the subgrade quality, is at the lower one-third of the base thickness. Abu-Farsakh et al. (2011) and Qian et al. (2012) reported that a geogrid with triangular aperture shape provides better improvement compared with the biaxial geogrid with similar tensile moduli.

A set of numerical analyses is performed in this study using PLAXIS 3D software to investigate the optimum location of the reinforcement layer within the $\mathrm{ABC}$ layer and provide an insight into the reason for the improvement in performance. Two ABC layer thicknesses are modeled under "stationary" cyclic loading. Various radii of the loaded area are used in the analyses. The subgrade soil and ABC materials properties are defined within the context of the Hardening Soil small-strain (HS small-strain) constitutive models. The numerical model is validated using data from field study reported by Mousavi et al. (2016).

\section{SOIL CONSTITUTIVE MODEL}

The Hardening Soil (HS) small strain constitutive model was implemented in this study because of its capability to incorporate the soil stiffness's nonlinear dependency on the strain level, as well as simulate the stiffness hardening due to an increase in confining pressure. The relationship between axial deviatoric stress and the axial strain was formulated first using the hyperbolic relationship developed by Konder (1963), and later implemented in the constitutive model by Duncan and Chang (1970), as expressed in Equation 1:

$$
-\varepsilon_{1}=\frac{1}{E_{i}} \frac{q}{1-q / q_{a}} \quad \mathrm{q}<\mathrm{q}_{\mathrm{f}}
$$

where $\mathrm{q}_{\mathrm{a}}$ and $\mathrm{E}_{\mathrm{i}}$ are defined as Equation 2 and 3:

$$
\mathrm{q}_{\mathrm{a}}=\frac{q_{f}}{R_{f}}
$$


Mousavi, Gabr, Borden

$$
\mathrm{E}_{\mathrm{i}}=\frac{2 E_{50}}{2-R_{f}}
$$

The $E_{50}$ is the stress dependent stiffness modulus which is given by Equation 4:

$$
E_{50}=E_{50}^{r e f}\left(\frac{c \cos \varphi-\sigma_{3}^{\prime} \sin \varphi}{c \cos \varphi+p^{r e f} \sin \varphi}\right)^{m}
$$

The stress dependency of $E_{50}$ is expressed by the power $m$. The $m$ value is recommended to be between 0.5 for sand and silt and 1.0 for soft clayey soil, (Janbu 1963; Von Soos 1990). Benz (2006) defined the shear stress-shear strain relationship in the context of the HS small-strain model, as expressed in Equation 5:

$$
\tau=G_{s} \gamma=\frac{G_{0}}{1+0.385\left|\frac{\gamma}{\gamma_{0.7}}\right|}
$$

The stress dependency of the shear modulus is given by Equation 6:

$$
G_{0}=G_{0}^{r e f}\left(\frac{c \cos \varphi-\sigma_{3}^{\prime} \sin \varphi}{c \cos \varphi+p^{r e f} \sin \varphi}\right)^{m}
$$

\section{INPUT MATERIAL PROPERTIES}

\section{ABC and Subgrade Layers}

The input materials properties were selected based on laboratory testing results, and numerical model validation using full-scale field testing results presented in Mousavi et al (2016). An ABC Class IV layer thickness of $203 \mathrm{~mm}$ (8 in.) was used over geogrid reinforcement to stabilize the soft subgrade during the full-scale testing phase. The in-situ subgrade soils were classified as SM and $\mathrm{ML}(\mathrm{A}-4, \mathrm{~A}-4 \mathrm{a})$, and $\mathrm{MH}(\mathrm{A}-7-5)$; these were Piedmont residual soils. The $\mathrm{ABC}$ and subgrade soils properties are summarized in Table 1. As will be discussed later, the analyses were performed for two thicknesses of $\mathrm{ABC}$ (203 and $305 \mathrm{~mm}$ ) layer. 
Mousavi, Gabr, Borden

\section{Geosynthetic}

The geosynthetic reinforcement was considered a geogrid and modeled as linear elastic materials. The only parameter needed for such representation is the normal elastic stiffness, $E A$, which is given by Equation 7:

$E A=\frac{T_{@ \varepsilon \%}}{\varepsilon}$

Where $T_{@ \varepsilon \%}$ is the axial strength at a given magnitude of strain, $\varepsilon \%$. The $E A$ values of 240 $\mathrm{kN} / \mathrm{m}(16200 \mathrm{lb} / \mathrm{ft})$ at a strain level of 5 percent, was selected for the geogrid reinforcements, as used in the full-scale testing reported by Mousavi et al. (2016). The interface layers are defined for both sides of the geogrid. A reduction factor of 1 (meaning no reduction in the interface strength, or $100 \%$ efficiency of the geogrid-backfill interface) was assigned to the interface of the geogrid and $\mathrm{ABC}$ and the geogrid and subgrade soil.

\section{LOADING CYCLE}

The shape of the applied cyclic loading was captured from Earth Pressure Cell (EPC) that recorded data during the full-scale testing phase of the study, as shown in Fig. 1. The radius of the loaded area was calculated as $147 \mathrm{~mm}$ (5.8 inches) corresponding to a tire pressure of 590 $\mathrm{kPa}(85 \mathrm{psi})$ and an axle load of $80 \mathrm{kN}(18,000 \mathrm{lb})$. Numerical analysis results reported by Mousavi (2016) indicated that the efficiency of the reinforcement in reducing surface deformation reaches a constant value after 100 load cycles. Therefore, results presented herein for comparative purpose correspond to 100 loading cycles in order to simplify the computational process and render the run time to manageable duration (typical run is about $24 \mathrm{hrs}$, for 100 load cycles). 
Mousavi, Gabr, Borden

\section{MODEL GEOMETRY}

The model domain extended $3048 \mathrm{~mm}$ (120 in.) in both the $X$ and $Y$ directions and $4572 \mathrm{~mm}$ (180 in.) in the $Z$ direction in order to eliminate the boundary effects and rebounding of the reflected wave into the zone impacted by loading (Howard and Warren 2009). The absorbent boundaries were considered for the $\mathrm{X}_{\max }, \mathrm{Y}_{\max }$, and $\mathrm{Z}_{\min }$ planes to absorb stress waves without rebounding into the soil body. A set of the general fixities applied imposed to the boundaries of the numerical model domain, as summarized in Table 2.

In order to eliminate the effect of the size of the generated mesh on the results, the ABC and soft A-4 subgrade soil were divided into three volumes, as shown in Fig. 2. Different combinations of coarseness factors were assigned to the soil volumes until no change in surface deformation under static loading of $590 \mathrm{kPa}(85 \mathrm{psi})$ was obtained. It was determined that maximum computed deformation does not change by utilizing more than 16000 elements in the model geometry. More details on mesh sensitivity analyses can be found on Mousavi et al. (2016).

\section{NUMERICAL ANALYSES RESULTS}

Optimum reinforcement location within the $\mathrm{ABC}$ layer was investigated for $\mathrm{ABC}$ with a thickness $(\mathrm{H})$ of 203 and $305 \mathrm{~mm}$ (8, and 12 in.) respectively. The effect of any matric suction was ignored and the surface deformation was computed under loaded areas with a radii (r) of 76, 152, and $305 \mathrm{~mm}(3,6$, and 12 in.), respectively. The reinforcement layer was located at various depths (D) from the surface, as summarized in Table 3.

\section{Effect of Reinforcement Location}

Fig. 4 shows the computed permanent surface deformation of the reinforced sections after 100 load cycles. Data in Fig. 4 are for three loaded areas with radii of 76, 152, and $305 \mathrm{~mm}$, 
Mousavi, Gabr, Borden

respectively, and two ABC thicknesses of 203 and $305 \mathrm{~mm}$. As shown in Fig. 4, the permanent surface deformation of the reinforced section depends on reinforcement depth (D), presented here in terms of the ratio of embedded depth to the radius of loaded $(\mathrm{D} / \mathrm{r})$. The results are in good agreement with data presented by Al-Qadi et al. (2012), Abu-Farsakh et al. (2011) Saad et al. (2006). Although these studies recommend an optimum location of the reinforcement layer based on the ABC thickness, no provision was made for the size of the loaded area. The numerical analyses results presented in Fig 4. indicated that the surface deformation for reinforced sections, with the two $\mathrm{ABC}$ layer thicknesses, is minimized when the reinforcement layer is placed at $\mathrm{D} / \mathrm{r}=0.5$. The significance of this ratio, in view of the size of the loaded area, is discussed later.

Fig. 5 shows the surface deformation after 100 load cycles, in terms of D/H ratio. It can be seen that the location which provides the maximum efficiency of the reinforcement inclusion depends on the radius of the loaded area and does not seem to be a function of the ABC layer thickness. It was observed that placing the reinforcement layer at a depth equal to half of the radius of loaded area, as compared to placing it at the interface between the $\mathrm{ABC}$ and the subgrade layers, can significantly decrease the surface deformation.

Fig. 6 shows the variation of vertical strain with depth beneath the center of the loaded area, for the unreinforced section, after 100 loaded cycles for ABC layer with a thickness of $203 \mathrm{~mm}(8$ in.). In this case, the maximum vertical strain occurs at the depth that approximately equal half of the radius of the loaded area $(\mathrm{z}=0.5 . \mathrm{r})$; which is consistent with Schmertmann (1970)'s strain influence diagram under squarely loaded area. Accordingly, it is hypothesized that the reinforcement layer should be placed at the depth corresponding to maximum vertical strain to improve efficiency of the reinforcement contribution. 
Mousavi, Gabr, Borden

\section{Mobilized Tension Force}

Variation of mobilized tension force in the reinforcement element with respect to its embedded depth was investigated under each loaded area. Plaxis 3D calculates mobilized tension force in the reinforcement layer in two local directions 1 and 2, based on the deformation in these directions, as demonstrated in Fig. 7 and expressed in Equations 8 and 9:

$$
N_{1}=E A_{1} \varepsilon_{1}
$$

$N_{2}=E A_{2} \varepsilon_{2}$

In this case N1, U1 and N2, U2 are in XX and YY direction respectively. As shown in Figs. 8 (ab), it was observed that the software does not rotate the local axis (U1 and U2) directions as the planes start to deform under the applied load. In this case, the software maintains U1 and U2 parallel and equal to $\mathrm{Ux}$ and $\mathrm{Uy}$ of the reinforcement node, respectively. Accordingly, the computed mobilized force in the geogrid is independent of the vertical deformation $(\mathrm{Uz})$, and is only contingent upon the horizontal deformation in XY plane. Therefore, manual computation of the force in the reinforcement is necessary.

In order to compute the mobilized tension force in the geogrid elements taking into account $\mathrm{Uz}$, the mobilized tension force was hand calculated by using Plaxis Ux and Uz output for each case. Fig. 9(a) shows the diagram of the 2 nodes of one geogrid element, with their Uz, and Ux, deformation in ZZ and XX direction. Fig. 9(b) illustrates how the new element length, L2, is calculated based on the relative nodes deformation, as expressed in Equation 10:

$$
L 2=\sqrt{\left(L 1+\left(U x_{2}-U x_{1}\right)\right)^{2}+\left(U z_{1}-U z_{2}\right)^{2}}
$$


Mousavi, Gabr, Borden

Equations 11 and 12 formulate in-plane strain of geogrid and mobilized tension force, respectively:

$$
\begin{aligned}
& \varepsilon=\frac{L 2-L 1}{L 1} \\
& F=(E A) \cdot \varepsilon
\end{aligned}
$$

Fig. 10 shows the hand calculated maximum mobilized tension force in geogrid elements after 100 load cycles, as a function of the $\mathrm{D} / \mathrm{r}$ ratios used in this study. It was observed that greater tension force is mobilized when reinforcement is implemented at the depth where maximum vertical strain occurs. Therefore, this explains the observation that permanent surface deformation is minimized when the reinforcement layer is placed at the depth at which maximum vertical strain occur $(D=0.5 r)$, with such a depth being a function of the diameter of the loaded area.

\section{Influence of Reinforcement Inclusion}

Fig. 11 shows the effectiveness of the reinforcement inclusion in terms of the ratio of $\mathrm{D} / \mathrm{r}$, for two thickness of ABC. The effective is represented by efficiency factor $(\eta)$ which calculated as presented in Equation 13. It was observed that the FEM results are consistent with the literature, which provided improvement with reinforcement is more pronounced with a thinner thickness of ABC (Fannin and Sigurdsson 1996; Hufenus et al. 2006; Cote et al. 2010; Al-Qadi 2012). As shown in Fig. 11, reinforcement inclusion can be ineffective if it is not implemented at the appropriate location. It can be seen that the efficiency of the geogrid can significantly increase from less than $5 \%$ to more than $70 \%$ if the reinforcement is located at the proposed optimum location of $\mathrm{D} / \mathrm{r}=0.5$. 
Mousavi, Gabr, Borden

Efficiency: $\eta=\frac{\delta_{\text {unreinforced }}-\delta_{\text {reinforced }}}{\delta_{\text {unreiforced }}}$

\section{CONCLUSIONS}

Numerical analyses were performed using Plaxis 3D and cyclic loading to evaluated the optimum location of a reinforcement layer such that the efficiency of the reinforcement inclusion is improved in an unpaved road section. The analyses results are also used to explain a key factor for improvement of performance. Based on the analyses results, the following conclusions can be drawn:

- Regardless of the $\mathrm{ABC}$ layer thickness, the surface deformation is minimized when the reinforcement is embedded at a depth of about half of the radius of loaded area, $(\mathrm{D} / \mathrm{r}=$ $0.5)$.

- The inclusion of reinforcement can lead to even smaller surface deformation if it is placed at the depth at which maximum vertical strain occur. This is especially important in cases with larger $\mathrm{ABC}$ thickness where the reinforcement is conventionally located at the interface of the base and subgrade layers.

- Computed mobilized force in geogrid in Plaxis 3D, under vertical load, seems to be incorrect at the force is computed independent of the vertical deformation. Vertical deformation is a main component that along with horizontal deformation (in XY plane) define the deformed shape of the geogrid layer and therefore the mobilizes force.

- A higher tension force is mobilized in reinforcement elements when the layer is placed at a depth corresponding to the maximum vertical strain ( in this paper it was at $\mathrm{D}=0.5 \mathrm{r}$ ). Thus reinforcement inclusion is more beneficial in the reduction of permeant surface deformation. 
Mousavi, Gabr, Borden

- The numerical analyses results confirmed data in literature indicating that reinforcement produces a higher reduction in surface deformation with thinner $\mathrm{ABC}$ layer. However, the additional finding of higher efficiency of reinforcement contribution when the layer is placed at $\mathrm{D} / \mathrm{r}=0.5$ further explains that the issue is more related to the location of the reinforcement layer rather than to the mere $\mathrm{ABC}$ layer thickness.

\section{LIST OF NOTATIONS}

m: Stress-dependent stiffness according to a power law.

$E_{50}^{r e f}$ : plastic straining due to primary deviatoric loading at $50 \%$ strength, at reference pressure

$E_{\text {oed }}^{\text {ref }}$ : Plastic straining due to primary compression, at reference pressure

$E_{u r}^{r e f}:$ elastic unloading/reloading, at reference pressure

$v_{u r}$ : unloading/reloading Poisson's ratio

$\mathrm{G}_{0}$ : initial shear modulus.

Gs: secant shear modulus

$\gamma_{0.7}$ : shear strain level at which the Gs is reduced to 70 percent of the $\mathrm{G}_{0}$ value

$q_{f}:$ ultimate deviatoric stress

$\mathrm{R}_{\mathrm{f}}$ : failure ratio

c: cohesion

$\sigma_{3}^{\prime}$ : effective confining pressure

$\varphi$ : friction angle

$p^{r e f}:$ reference pressure $($ etc, 1 atm $=100 \mathrm{kPa}$ )

$\mathrm{S}_{\mathrm{u}}$ : undrained shear strength

EA: normal elastic stiffness

Ui: deformation in direction $\mathrm{i}$

D: reinforcement embedded depth

r: radius of the loaded area

$\delta_{z}:$ surface deformation 
Mousavi, Gabr, Borden

H: thickness of aggregate base course

Ni: mobilized force in reinforcement in direction $\mathrm{i}$

\section{REFERENCES}

Abu-Farsakh, M., Souci, G., Voyiadjis, G. Z., and Chen, Q. 2011. Evaluation of factors affecting the performance of geogrid-reinforced granular base material using repeated load triaxial tests. Journal of Materials in Civil Engineering, 24(1), 72-83.

Al-Qadi, I. L., Dessouky, S. H., Kwon, J., and Tutumluer, E. 2012. Geogrid-reinforced lowvolume flexible pavements: Pavement response and geogrid optimal location. Journal of Transportation Engineering, 138(9), 1083-1090.

Benz, T. 2006. Small-strain stiffness of soils and its numerical consequences. Ph.D thesis, university of Stuttgard.

Brinkgreve, R.B.J. 2010. "Plaxis Materials Models Manual”.

Cancelli, A., and Montanelli, F. 1999. In-ground test for geosynthetic reinforced flexible paved roads (No. Volume 2).

Chen, Q., Abu-Farsakh, M., and Tao, M. 2009. Laboratory evaluation of geogrid base reinforcement and corresponding instrumentation program. ASTM geotechnical testing journal, 32(6), 516-525.

Cote, B., Robinson, B., Pyo, S., Park, Y. J., Gabr, M., and Borden, R. 2010. Laboratory performance comparison of stabilized undercut subgrade under cyclic loading. ASTM geotechnical testing journal, 33 (6) pp. 453-462.

Cowell, T. D., Pyo, S. C., Gabr, M. A., and Borden, R. H., 2012, "Field Verification of Undercut Criteria and Alternatives for Subgrade Stabilization - Coastal Plain", Publication FHWA/NC/2008-13, FHWA, U.S. Department of Transportation.

Duncan, J. M., and Chang, C.Y. 1970. Nonlinear analysis of stress and strain in soil. ASCE J. of soil Mech. And Found. Div., 96, 1629-1653.

Fannin, R. J., and Sigurdsson, O. 1996. "Field Observations on Stabilization of Unpaved Roads with Geosynthetics". Journal of Geotechnical Engineering, 544-553.

Howard, I. L., and Warren, K. A. 2009. Finite-element modeling of instrumented flexible pavements under stationary transient loading. Journal of Transportation Engineering, 135(2), 531.

Hufenus, R., Rueegger, R., Banjac, R., Mayor, P., Springman, S. M., and Bronnimann, R. 2006. "Full-scale field test on geosynthetic reinforced unpaved roads on soft subgrades". Geotextiles and Geomembranes, 24, 21-37. 
Janbu, N. 1963. October. Soil compressibility as determined by oedometer and triaxial tests. In Proceedings of the European conference on soil mechanics and foundation engineering (Vol. 1, pp. 19-25).

Kondner, R.L. 1963. A hyperbolic stress strain formulation for sand. 2. Pan. Am. ICOSFE Brazil, 1, 289-324.

Leng, J., and Gabr, M. A. 2005, "Numerical Analysis of Stress-deformation Response in Reinforced Unpaved Road Sections”, Geosynthetics International, Vol.12, No.2, pp.111-119.

Mousavi, S. H., Gabr, M. A., and Borden, R.H. 2016. "Filed Verification of Undercut Criteria and Alternatives for Subgrade Stabilization in the Piedmont Area of North Carolina".FHWA/NC/2011-05

Palmeira E.M. and Gongora I.A.G. 2015. Assessing the influence of soil-reinforcement interaction parameters on the performance of a low fill on compressible subgrade — part I: fill performance and relevance of interaction parameters. Int $J$ Geosynth. Ground Eng. doi:10.1007/s40891-015-0041-3.

Perkins, S. W. 1999b. "Geosynthetic Reinforcement of Flexible Pavements: Laboratory Based Pavement Test Sections, Federal Highway Administration Report FHWA/MT-99-001/8138, Montana Department of Transportation, $140 \mathrm{p}$.

Perkins, S. W., Ismeik, M. and Fogelsong, M. L. 1999. "Influence of Geosynthetic Placement Position on the Performance of Reinforced Flexible Pavement Systems," Proceedings of the Conference Geosynthetics '99, Boston, MA, USA, Vol. 1, pp. 253-264.

Qian, Y., Han, J., Pokharel, S. K., and Parsons, R. L. 2012. Performance of triangular aperture geogrid-reinforced base courses over weak subgrade under cyclic loading. Journal of Materials in Civil Engineering, 25(8), 1013-1021.

Saad, B., Mitri, H., and Poorooshasb, H. 2006. 3D FE analysis of flexible pavement with geosynthetic reinforcement. Journal of transportation Engineering, 132(5), 402-415.

Saghebfar, M. 2014, performance of geotextile-reinforced bases for paved roads. Ph.D dissertation, Kansas State University.

Schmertmann, J.H. 1970. Static cone to compute static settlement over sand. Journal of the Soil Mechanics and Foundations Division, ASCE, 96(3): 1011-1043.

Sun, X., Han, J., Kwon, J., Parsons, R. L., and Wayne, M. H. 2015. Radial stresses and resilient deformations of geogrid-stabilized unpaved roads under cyclic plate loading tests. Geotextiles and Geomembranes, 43(5), 440-449.

Tang, X., Abu-Farsakh, M., Hanandeh, S., and Chen, Q. 2015. Performance of Reinforcedstabilized Unpaved Test Sections Built over Native Soft Soil Under Full-Scale Moving Wheel Loads. Transportation Research Record: Journal of the Transportation Research Board, (2511), 81-89.

Thakur, J. K., Han, J., Pokharel, S. K., and Parsons, R. L. 2012. Performance of geocellreinforced recycled asphalt pavement (RAP) bases over weak subgrade under cyclic plate loading. Geotextiles and Geomembranes, 35, 14-24. 
Mousavi, Gabr, Borden

Tingle, J. S., and Jersey, S. R. 2009. "Full-Scale Evaluation of Geosynthetic-Reinforced Aggregate Roads". Transportation Research Record: Journal of Transportation Research Board, No. 2116, 96-107.

Von Soos, P. 1990. Properties of Soil and Rock (in German), Grundbau Taschenbuch Part 4.

White, D. J., Vennapusa, P. K. R., Gieselman, H. H., Douglas, S. C., Zhang, J., and Wayne, M. H. 2011. In-ground dynamic stress measurements for geosynthetic reinforced subgrade/subbase. In Geo-Frontiers Congress 2011. 
Mousavi, Gabr, Borden

\section{Figure Captions}

Figure 1. One applied load cycle.

Figure 2. Model geometry and soil volumes.

Figure 3. Location of the reinforcement layer.

Figure 4. Surface deformation vs $\mathrm{D} / \mathrm{r}$.

Figure 5. Surface deformation vs D/H.

Figure 6. Vertical strain distribution with depth after 100 load cycles, under center of loaded area for unreinforced unpaved section with H: $203 \mathrm{~mm}$.

Figure 7. Local force, deformation and strain axis (After Plaxis 3D).

Figure 8. (a) Ux, (b) U1, of geogrid after 100 load cycles; H, D, and r= $305 \mathrm{~mm}$, legends are in inches $(1 \mathrm{in} .=25.4 \mathrm{~mm})$.

Figure 9. (a) Deformed geogrid nodes, (b) relative deformation of geogrid nodes.

Figure 10. Maximum mobilized tension force in the geogrid after 100 load cycles.

Figure 11. Influence of reinforcement inclusion. 
Mousavi, Gabr, Borden

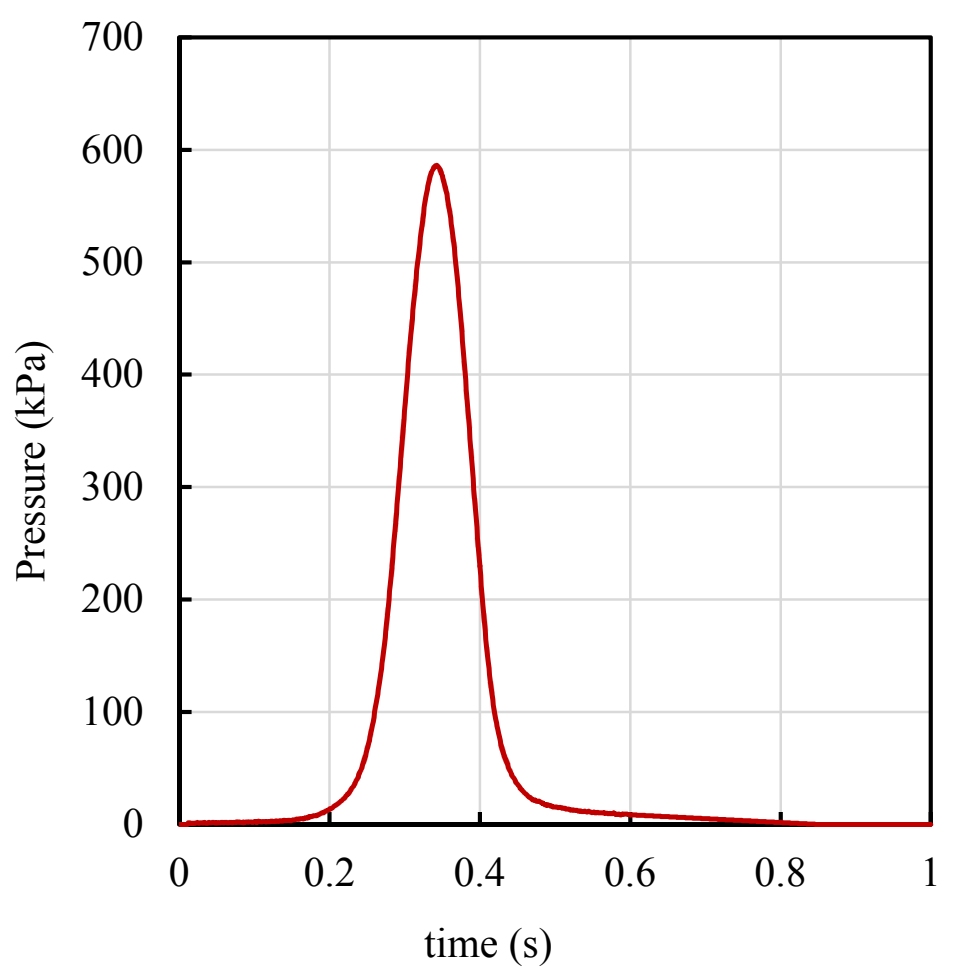

Figure 1. One applied load cycle. 
Mousavi, Gabr, Borden

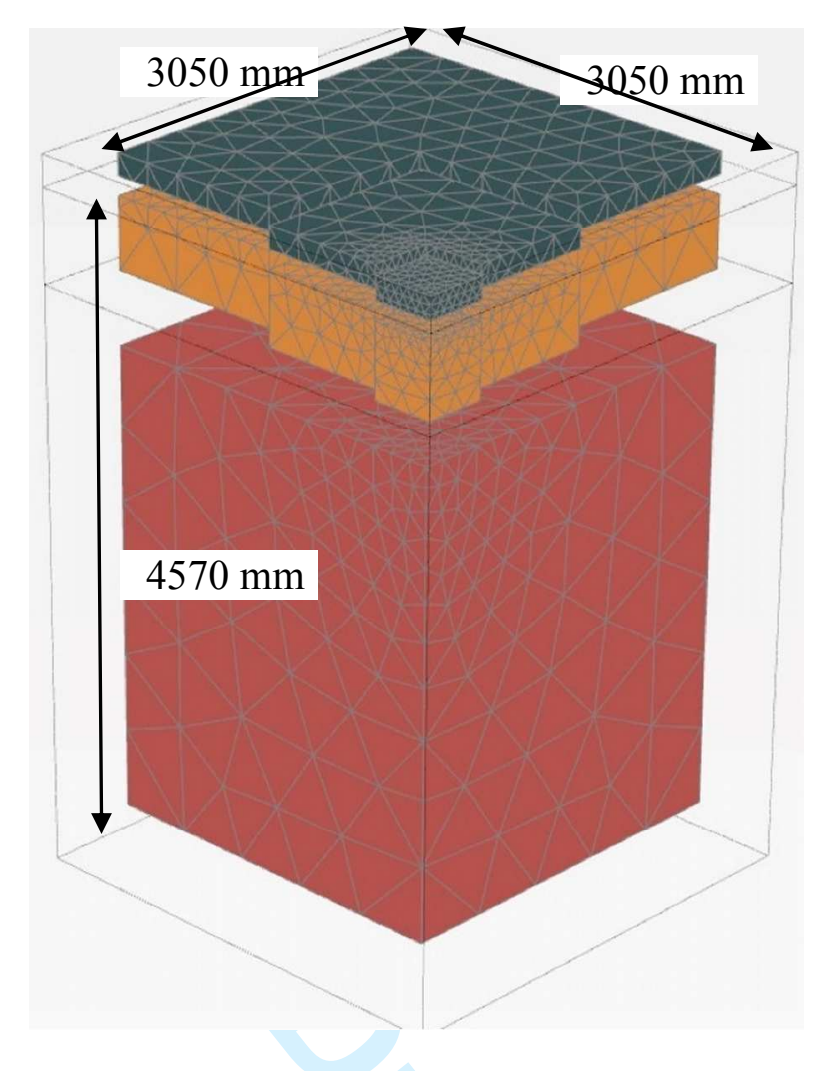

Figure 2. Model geometry and soil volumes. 
Mousavi, Gabr, Borden

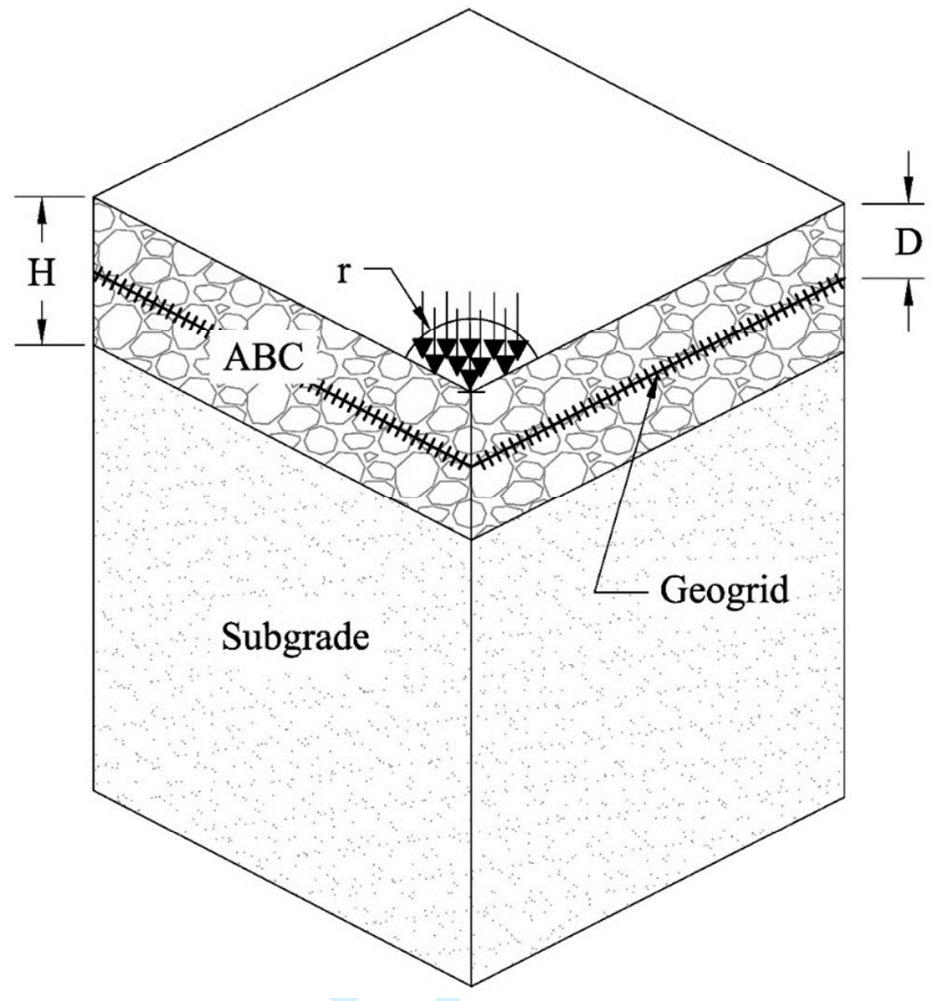

Figure 3. Location of the reinforcement layer. 
Mousavi, Gabr, Borden

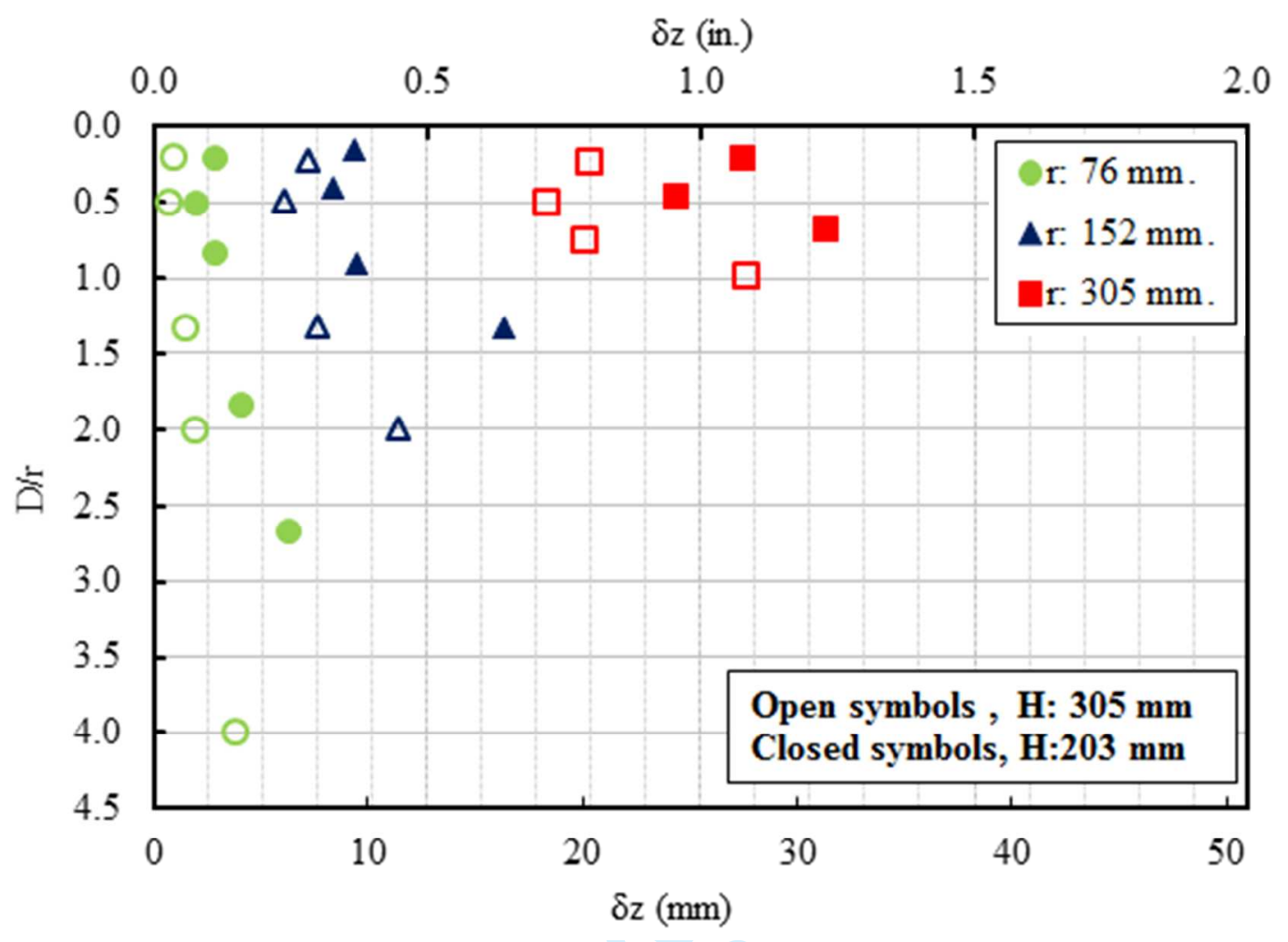

Figure 4. Surface deformation vs $D / r$. 
Mousavi, Gabr, Borden

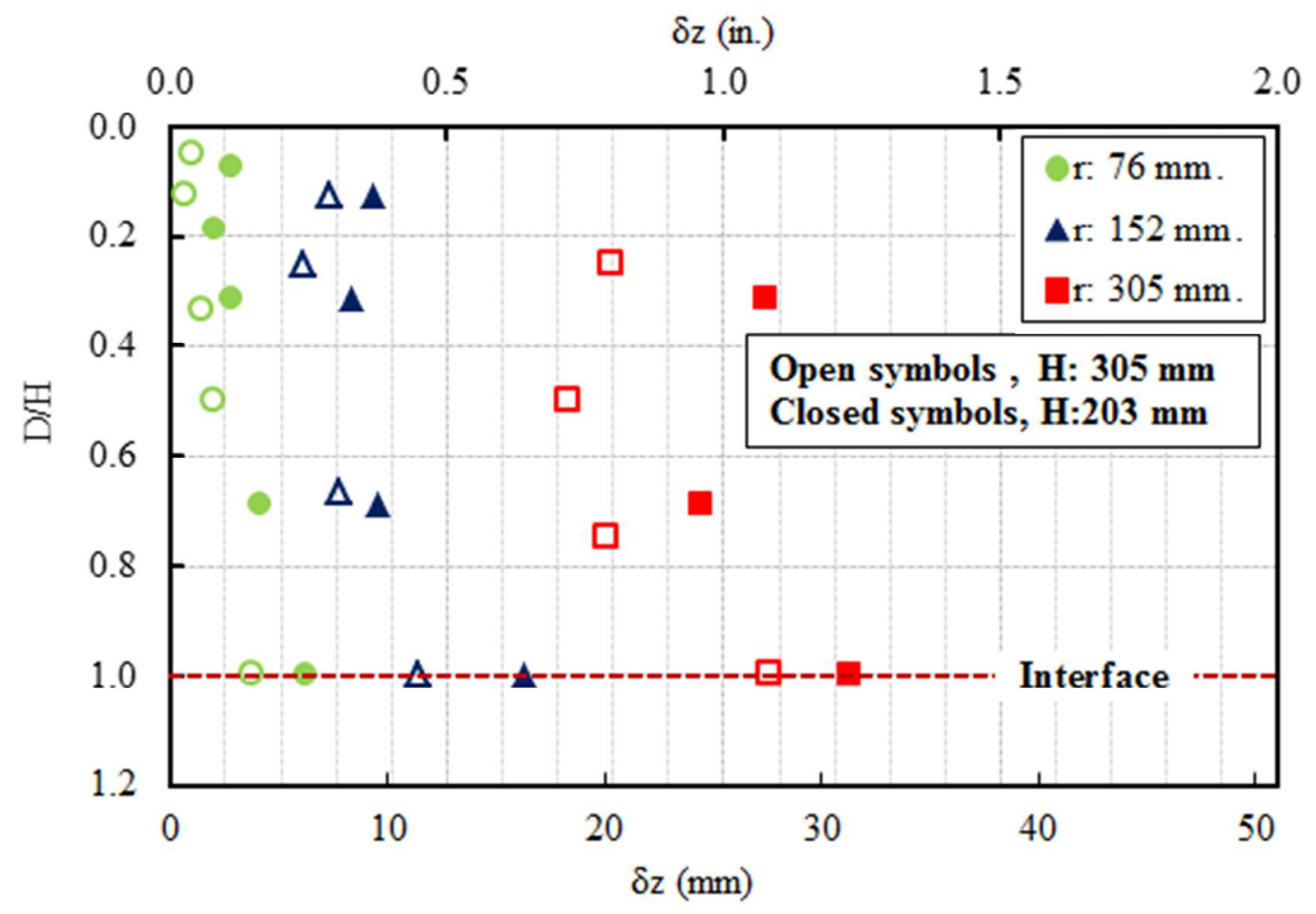

Figure 5. Surface deformation vs D/H. 
Mousavi, Gabr, Borden

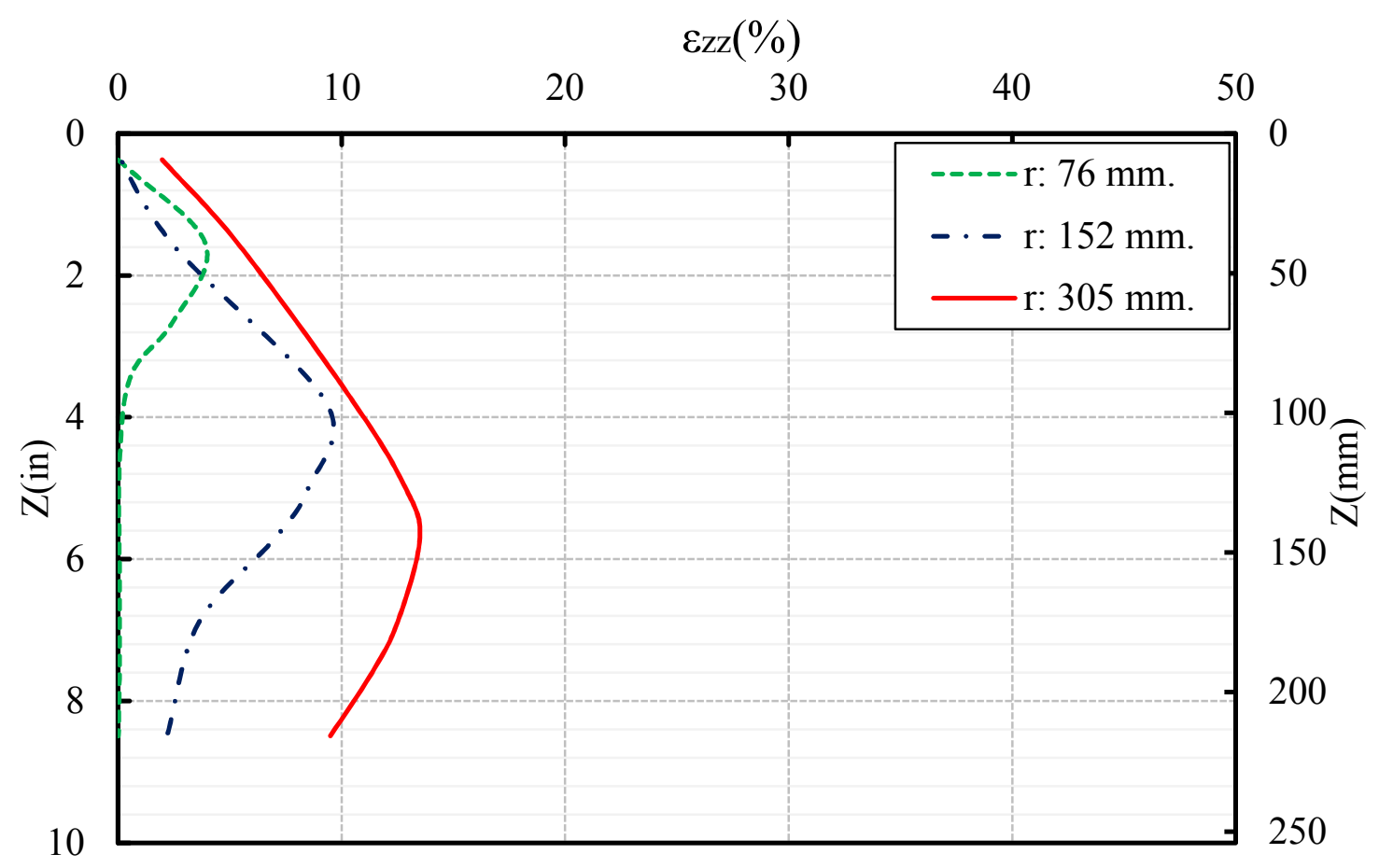

Figure 6. Vertical strain distribution with depth after 100 load cycles, under center of loaded area for unreinforced unpaved section with $\mathrm{H}: 203 \mathrm{~mm}$. 
Mousavi, Gabr, Borden

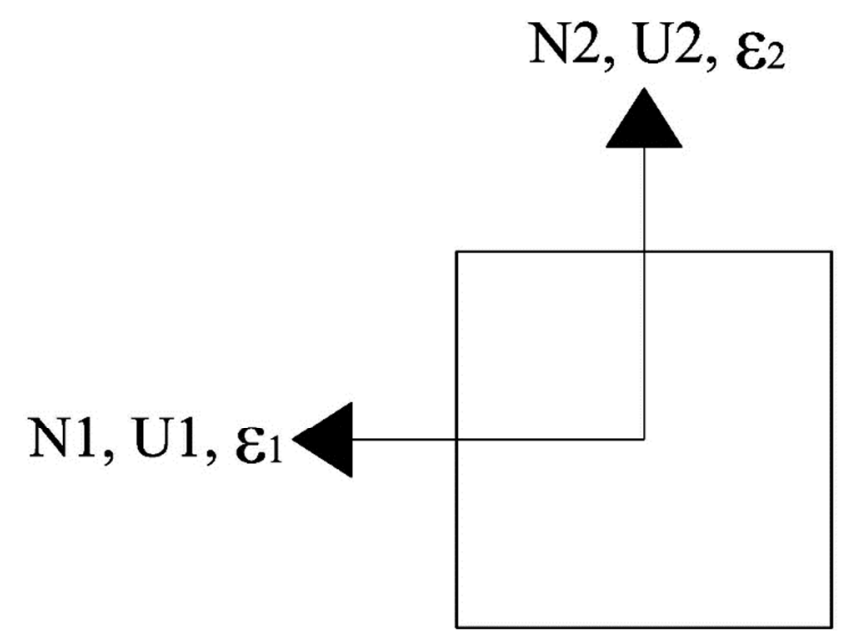

Figure 7. Local force, deformation and strain axis (After Plaxis 3D). 
Mousavi, Gabr, Borden

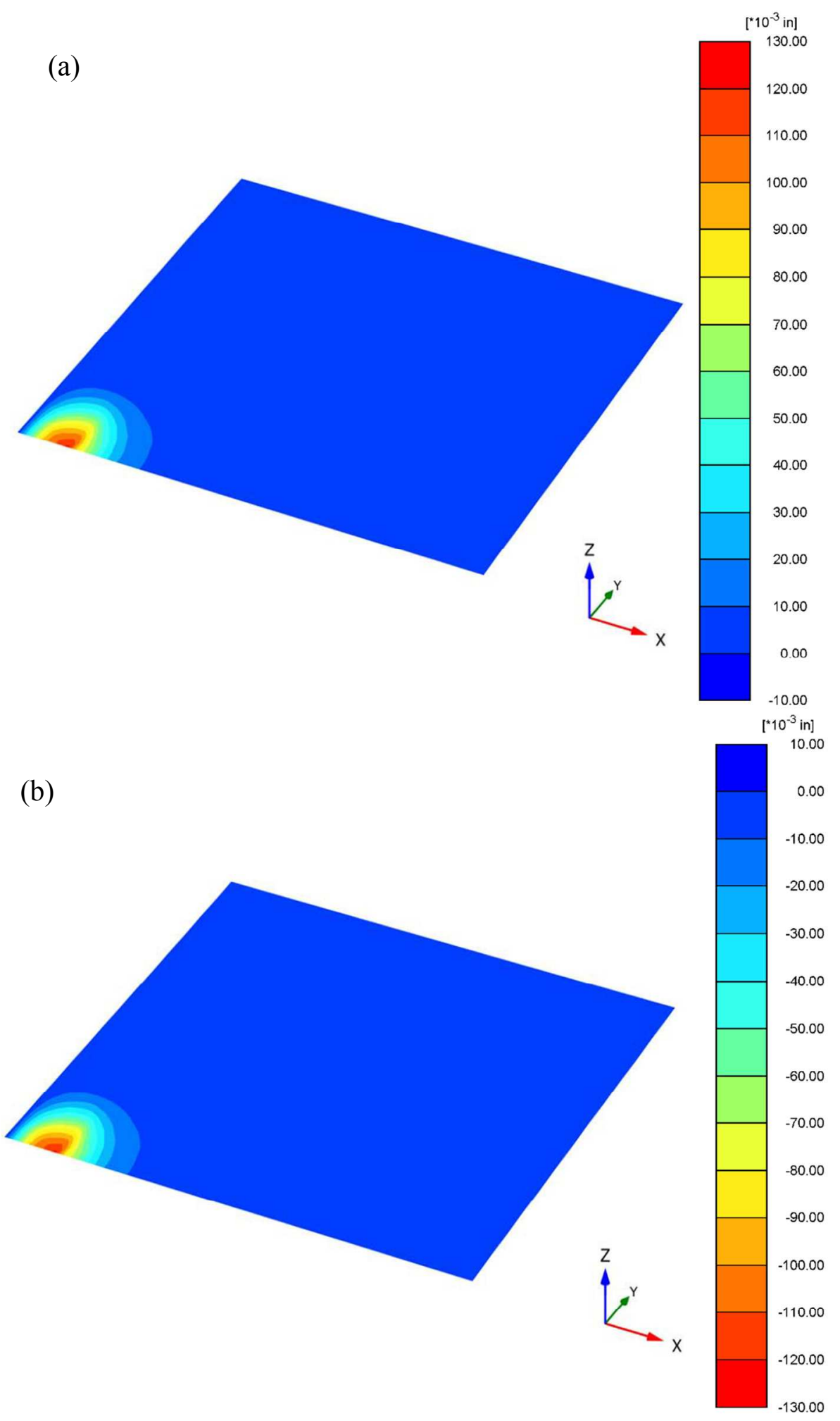

Figure 8. (a) Ux, (b) U1, of geogrid after 100 load cycles; H, D, and r= $305 \mathrm{~mm}$, legends are in inches $(1$ in. $=25.4 \mathrm{~mm})$. 
Mousavi, Gabr, Borden

(a)

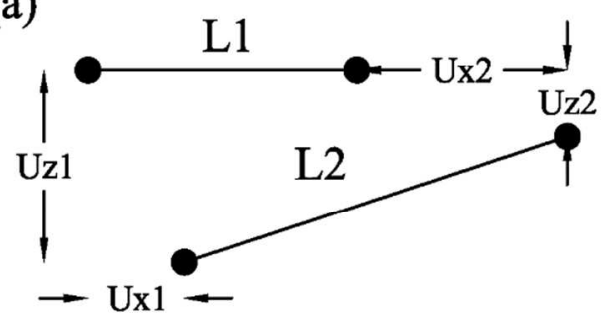

(b)

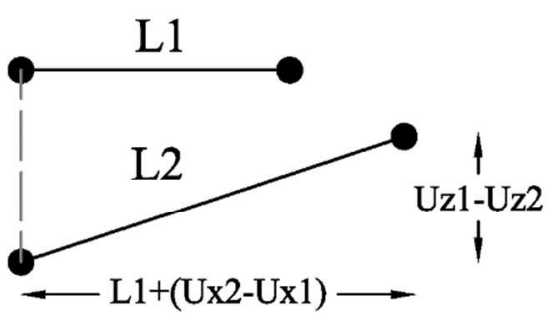

Figure 9. (a) Deformed geogrid nodes, (b) relative deformation of geogrid nodes. 
Mousavi, Gabr, Borden

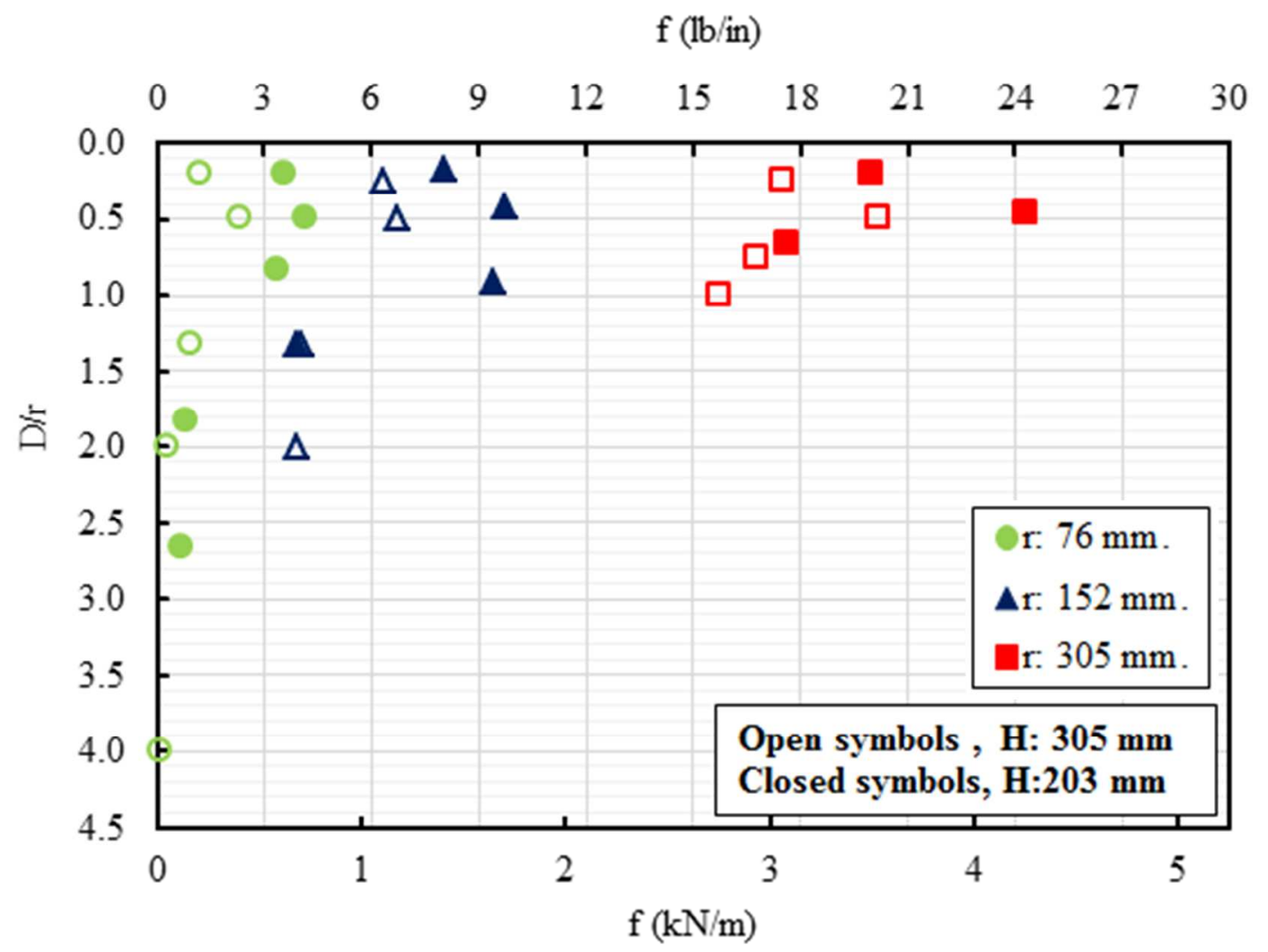

Figure 10. Maximum mobilized tension force in the geogrid after 100 load cycles. 
Mousavi, Gabr, Borden

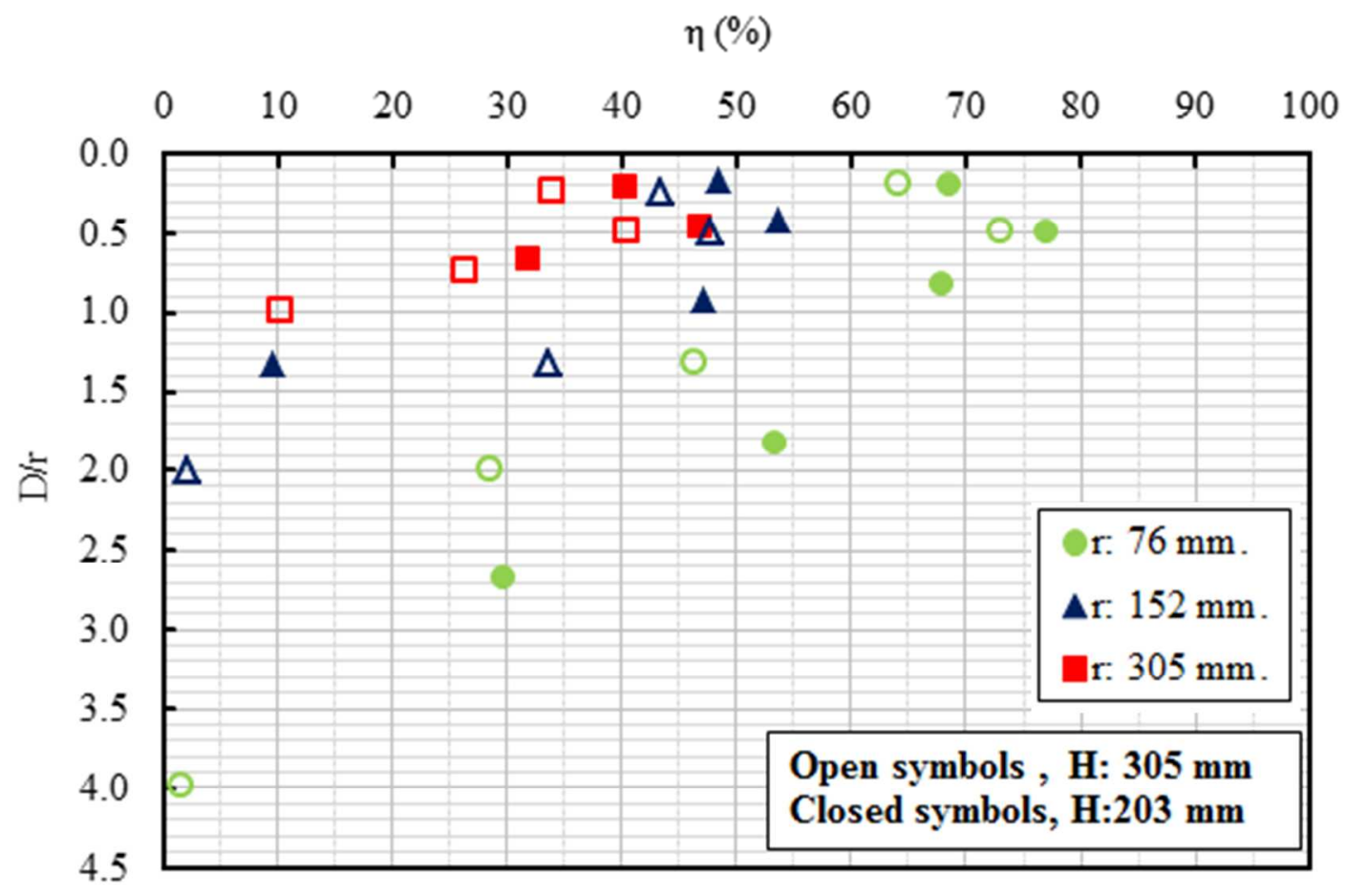

Figure 11. Influence of reinforcement inclusion. 
Mousavi, Gabr, Borden

Table 1. ABC and Subgrade Soils Properties Used in Numerical Analyses.

\begin{tabular}{ccccccccccccc}
\hline \multirow{2}{*}{ Material } & $\begin{array}{c}\text { Thickness } \\
(\mathrm{mm})\end{array}$ & $\begin{array}{c}\gamma_{\text {mist }} \\
\left(\mathrm{kN} / \mathrm{m}^{3}\right)\end{array}$ & $\begin{array}{c}E_{50}^{\text {ref }} \\
(\mathrm{MPa})\end{array}$ & $\begin{array}{c}E_{\text {oed }}^{\text {ref }} \\
(\mathrm{MPa})\end{array}$ & $\begin{array}{c}E_{u r}^{\text {ref } 2} \\
(\mathrm{MPa})\end{array}$ & $\mathrm{m}$ & $v_{u r}$ & $\begin{array}{c}G_{0}^{\text {ref }} \\
(\mathrm{ksi})\end{array}$ & $\begin{array}{c}\gamma_{0.7} \\
(\%)\end{array}$ & $\varphi^{\prime}$ & $\mathrm{c}^{\prime} / \mathrm{s}_{\mathrm{u}}(\mathrm{kPa}) \mathrm{R}_{\mathrm{f}}$ \\
\hline $\mathrm{ABC}$ & - & 23 & 200 & 180 & 400 & 0.64 & 0.2 & 800 & 0.05 & 43 & 0 & 0.9 \\
$\mathrm{~A}-4$ & 610 & 20 & 75 & 75 & 150 & 0.5 & 0.2 & 360 & 0.001 & 25 & 13.8 & 0.9 \\
$\mathrm{~A}-7-5$ & 3760 & 19 & 48 & 24 & 150 & 1 & 0.2 & 550 & 0.003 & $\mathrm{NA}$ & 193 & 0.9 \\
\hline
\end{tabular}


Mousavi, Gabr, Borden

Table 2. Geometry Boundary Conditions.

\begin{tabular}{lll}
\hline Plane & Deformation fixities & Deformation \\
\hline X min & Normally fixed & $\mathrm{Ux}=0$ \\
X max & Normally fixed & $\mathrm{Ux}=0$ \\
Y min & Normally fixed & $\mathrm{Uy}=0$ \\
$Y$ max & Normally fixed & $\mathrm{Uy}=0$ \\
$Z$ min (bottom) & Fully fixed & $\mathrm{Ux}=\mathrm{Uy}=\mathrm{Uz}=0$ \\
$Z$ max (surface) & Free & free \\
\hline
\end{tabular}


Mousavi, Gabr, Borden

Table 3. Reinforcement depth.

\begin{tabular}{ccccccc}
\hline $\mathrm{H}(\mathrm{mm})$ & $\mathrm{r}(\mathrm{mm})$ & & & $\mathrm{D} / \mathrm{H}$ & & \\
\hline \multirow{3}{*}{203} & 76 & 1 & 0.69 & 0.31 & 0.08 & 0.19 \\
& 152 & 1 & 0.69 & 0.31 & 0.13 & \\
& 305 & 1 & 0.69 & 0.31 & & 0.05 \\
\cline { 2 - 7 } 305 & 76 & 1 & 0.50 & 0.33 & 0.13 & \\
& 152 & 1 & 0.67 & 0.25 & 0.13 & \\
& 305 & 1 & 0.75 & 0.50 & 0.25 & \\
\hline
\end{tabular}

